Available online at https://jurnal.stmikroyal.ac.id/index.php/jurdimas

\title{
PELATIHAN KOMUNIKASI ASERTIF BAGI KADER ASI HEBAT JEJARING KESEHATAN PURWOKERTO UTARA
}

\author{
Ade Tuti Turistiati ${ }^{1 *}$, Prita Suci Nurcandrani ${ }^{1}$, Rahmawati Putri ${ }^{1}$, Endah Nurkhalida ${ }^{2}$ \\ ${ }^{1}$ Program Studi Ilmu Komunikasi, Universitas Amikom Purwokerto \\ ${ }^{2}$ Puskesmas Purwokerto Utara 2 \\ email:*ade.tuti@amikompurwokerto.ac.id
}

\begin{abstract}
The exclusive breastfeeding coverage in the work area of North Community Health Center (Puskesmas Purwokerto Utara) 2 had only reached $76 \%$ by mid-2020. To pursue the target of achieving $90 \%$ by the end of the year, cross-sectoral cooperation is needed. Lecturers of The Communication Science Study Program of Universitas Amikom Purwokerto took the initiative as facilitators by partnering with North Community Health Center staff to conduct a community service as an implementation of the Tri Dharma of Higher Education. In this event, the facilitators conducted socialization and training methods for health cadres on how to communicate assertively with breastfeeding mothers by emphasizing acceptance, empathy, support and openness. The training was carried out for one week, included four villages within the Community Health Center working area, namely Grendeng, Bancarkembar, Sumampir and Pabuwaran. This community service has a good impact to the health cadres and The Community Health Center. The 90\% target of exclusive breastfeeding will be reviewed by the end of 2021 . However, the health cadres and The Community Health Center have more self-confidence to convince breastfeeding mothers to look after their children better by giving them the exclusive breastfeeding. In turn, the target will be achieved.
\end{abstract}

Keywords: assertive communication; cross sectorial cooperation; exclusive breastfeeding.

\begin{abstract}
Abstrak: Cakupan ASI Eksklusif di wilayah kerja Puskesmas Purwokerto Utara 2 baru mencapai $76 \%$ pada pertengahan tahun 2020. Untuk mencapai target $90 \%$ cakupan ASI Eksklusif pada akhir tahun, dibutuhkan kerjasama lintas sektoral. Dosen Program Studi Ilmu Komunikasi Universitas Amikom Purwokerto berinisiatif menjadi fasilitator dengan bermitra dengan Puskesmas dalam melakukan pengabdian masyarakat sebagai bentuk pelaksanaan Tri Dharma Perguruan Tinggi. Pada kegiatan ini fasilitator menggunakan metode sosialisasi dan pelatihan kepada kader kesehatan tentang bagaimana berkomunikasi secara asertif dengan mengedepankan penerimaan, empati, dukungan dan keterbukaan kepada ibu menyusui. Pelatihan dilakukan selama satu minggu, dan meliputi empat desa yang berada dalam wilayah kerja puskesmas, yaitu Grendeng, Bancarkembar, Sumampir dan Pabuwaran. Pengabdian kepada masyarakat ini mempunyai dampak baik terhadap kader kesehatan dan Puskesmas. Target $90 \%$ ibu menyusui memberikan ASI eksklusif akan direview pada akhir tahun 2021. Namun, para kader kesehatan dan Puskesmas merasa lebih percaya diri dapat meyakinkan kepada para ibu menyusui untuk dapat memberikan ASI eksklusif kepada anak-anaknya dan pada gilirannya target tersebut dapat tercapai.
\end{abstract}

Kata kunci: ASI eksklusif; kerja sama lintas sektoral; komunikasi asertif. 
Available online at https://jurnal.stmikroyal.ac.id/index.php/jurdimas

\section{PENDAHULUAN}

Ibu menyusui sering mengalami masalah dalam pemberian ASI, misalnya disebabkan oleh mastitis, bengkak, dan tidak nyaman. Terdapat kecenderungan ibu untuk tidak memberikan ASI jika mengalami hal tersebut, kecuali apabila mereka mendapat bantuan para profesional. Pengalaman tidak menyenangkan dalam proses menyusui akan memengaruhi keputusan ibu menyusui tentang pemberian makanan tambahan pada bayi.

Alasan lain yang cukup mendasari terjadinya penyapihan atau tidak diberikannya ASI lebih awal adalah ketakukan ibu tentang ketidak cukupan persediaan susu. Selain itu, rasa kurang percaya diri dan kurangnya pengetahuan yang mendalam yang dialami oleh ibu juga mengakibatkan persepsi yang kurang tepat mengenai pasokan ASI, walau pada kenyataannya, persediaan ASI dirancang cukup untuk memenuhi kebutuhan bayi(Mufdlilah, 2017).

Puskesmas Purwokerto Utara memiliki Program Inovasi Unggulan, yaitu Program Kasih Jeruk Purut (Kader ASI Hebat Jejaring Purwokerto Utara). Program tersebut menekankan pada tercapainya cakupan ASI hingga 90\% pada tahun 2021 di wilayah kerja Puskesmas Purwokerto Utara. Pencapaian target tersebut mempunyai beberapa tantangan yang harus dihadapi. Beberapa masalah yang dihadapi oleh para kader ASI Kasih Jeruk Purut dan staf Puskesmas di antaranya banyaknya ibu bekerja yang terkendala kesibukan kerja sehingga tidak dapat memberikan ASI eksklusif, kurangnya pengetahuan ibu menyusui tentang manajemen ASI perah, dan cukup banyaknya ibu menyusui yang memberikan makanan tambahan pada bayi di bawah usia 6 bulan.
Menurut Ketua Program Kasih Jeruk Purut cakupan ASI Eksklusif hingga akhir 2020 baru mencapai $76 \%$ atau masih di bawah 90\%. Selain itu, ada mitos yang berkembang di masyarakat bahwa sebaiknya bayi diberikan makanan tambahan atau MPASI (Makanan Pendamping ASI) lebih awal. Biasanya bayi di bulan-bulan awal sudah diberi pisang atau biskuit. Hal tersebut banyak terjadi pada bayi yang ibunya bekerja dengan alasan agar bayi menjadi lebih kenyang. Para ibu menyusui tersebut bekerja sebagai pelayan toko atau bekerja di pasar, pembantu rumah tangga, dan lain-lain. Rata-rata para ibu menyusui berpendidikan SMA sederajat. Bayi di bawah usia 6 bulan yang diberi MPASI, sangat beresiko mengalami gangguan usus. Selain itu pencernaan bayi pun belum siap dengan makanan padat.

MPASI atau Makanan Pendamping ASI adalah minuman atau makanan bergizi yang diberikan kepada bayi atau anak usia 6-24 bulan. MPASI bermanfaat untuk mencukupi kebutuhan gizi selain dari Air Susu Ibu. Selama enam bulan pertama, pemberian ASI secara eksklusif dan MPASI yang tepat dapat meningkatkan kelangsungan hidup anak lebih baik. Namun, kebutuhan gizi anak tidak cukup jika ibu memberikan ASI terlalu lama sementara pemberian MPASI ditunda. Makanan Pendamping ASI yang baik untuk anak, yaitu cara memberikannya dengan benar, tepat waktu, aman dikonsumsi, bergizi lengkap, cukup dan seimbang, (Sari \& Kumorojati, 2019).

Para kader ASI Kasih Jeruk Purut dan staf Puskesmas perlu memberikan pemahaman kepada para ibu menyusui mengenai pentingnya memberikan ASI eksklusif, kapan memberikan MPASI dan manfaatnya, serta akibat yang ditim- 
Available online at https://jurnal.stmikroyal.ac.id/index.php/jurdimas

bulkan apabila bayi mengalami kekurangan gizi, dan sebagainya.

Berdasarkan observasi dan wawancara langsung dengan Ketua Program Kasih Jeruk Purut, perlu adanya peningkatan keterampilan berkomunikasi yang lebih efektif antara petugas kesehatan dengan ibu menyusui. Dalam hal ini petugas kesehatan merangkap sebagai kader ASI yang berada di wilayah kerja Purwokerto Utara 2. Mereka adalah garda depan dalam membentuk sebuah pemahaman dan perubahan perilaku pada ibu menyusui.

Kemampuan berkomunikasi efektif perlu dimiliki oleh petugas kesehatan yang aktifitas sehari-harinya berkomunikasi dengan pasien dan klien seperti ibu menyusui. Komunikasi petugas kesehatan berbeda dengan komunikasi yang dilakukan oleh kebanyakan orang. Petugas kesehatan perlu mempunyai kompetensi khusus untuk mencapai tujuan komunikasinya.

Komunikasi akan efektif apabila dapat mengubah sikap seseorang. Gaya komunikasi asertif merupakan gaya komunikasi efektif yang dapat merubah perilaku seseorang. Penelitian Omura dkk menunjukkan bahwa hubungan perawat dan pasien berjalan lebih baik ketika perawat melakukan komunikasi asertif dengan pasiennya. Hal tersebut ditunjukkan oleh perilaku pasien yang dengan suka rela disiplin mengikuti aturan minum obat, istirahat, dan beraktifitas ringan (Omura, Levett-Jones, \& Stone, 2019).

Hasil penelitian Nezad menunjukkan bahwa komunikasi asertif ditandai dengan adanya pengetahuan tentang halhal yang perlu disampaikan, bagaimana berperilaku dalam kondisi yang beragam, serta bagaimana kita bereaksi terhadap perilaku atau respon orang lain. Selain itu, komunikator mempunyai penge- tahuan mengenai komunikan atau orang uang diajak berkomunikasi dan mengerti konten komunikasinya. Kualitas dan kuantitas pengetahuan tersebut terus meningkat seiring dengan semakin banyaknya pengalaman dan tingginya pendidikan seseorang. Kompetensi komunkasi seseorang akan meningkat jika orang tersebut lebih paham bagaimana caranya berkomunikasi dengan orang lain yang berbeda budaya dan situasinya beragam. (Hadavi \& Abdorrazagh Nejad, 2018).

Asertif adalah kemampuan individu untuk mengungkapkan pendapatnya dengan sikap jujur dan terbuka sambil memerhatikan emosi, pikiran, dan hak orang lain (Lambertz-Berndt \& Blight, 2016). Orang yang asertif adalah orang yang mengatakan apa yang ingin orang tersebut katakana dengan jelas, mempunyai kemampuan berempati, menghormati orang lain, dan mengatakan tidak (Uzuntarla, Cihangiroglu, Ceyhan, \& Ugrak, 2016).

Komunikasi asertif pada intinya adalah kemampuan untuk mengekspresikan ide negatif dan positif serta perasaaan dengan langsung secara terbuka, jujur, dan menghormati orang lain. Kita bertanggung jawab atas ucapan dan aksi kita tanpa menghakimi atau menyalahkan orang lain. Jika konflik terjadi, para pihak yang berkonflik mencari solusi bersama yang saling memuaskan kedua belah pihak.

\section{METODE}

Kegiatan pengabdian masyarakat ini menggunakan metode sosialisasi dan pelatihan komunikasi asertif kepada para kader kesehatan. Tahap awal metode sosialisasi adalah mengidentifikasi masalah. Pada tahap ini dilakukan wawancara 
Available online at https://jurnal.stmikroyal.ac.id/index.php/jurdimas

dan observasi langsung serta pengambilan data yang diperlukan. Kegiatan pelatihan ini dilakukan di Puskesmas Purwokerto Utara 2 dan empat kelurahan yang bernaung di wilayah kerja Puskesmas tersebut, yaitu Bancarkembar, Grendeng, Pabuwaran dan Sumampir. Selain wawancara dengan Ketua Program Kasih Jeruk Purut, tim pelaksana PKM melakukan wawancara dengan tiga kader serta tiga ibu menyusui yang mewakili masing-masing kelurahan tersebut.

Berdasarkan identifikasi yang didapatkan, dilanjutkan dengan perumusan identifikasi kebutuhan mitra berupa perlunya peningkatan komunikasi kader kesehatan dan kader ASI di wilayah kerja Puskesmas Purwokerto Utara 2. Total kader yang didapatkan dari data puskesmas berjumlah delapan hingga sepuluh orang di tiap kelurahan. Para kader ini rata-rata berusia di atas 35 tahun, ibu rumah tangga, dan sudah memiliki anak.

Pelaksaaan pelatihan kader kesehatan/ASI berlangsung dari tanggal 20-27 Juni 2020 atau selama satu minggu di empat kelurahan yang berbeda. Kegiatan ini berlangsung selama 2 jam di tiap-tiap kelurahan dengan dihadiri oleh pihak Puskesmas, Kepala Desa, Bhabinsa, Bhabinkamtibmas, dan para kader yang menjadi sasaran pelatihan. Kehadiran dari pihak luar tersebut merupakan sebuah sinergitas kerjasama lintas sektoral dalam upaya pencapaian angka cakupan ASI 90\%. Selama proses kegiatan pelatihan, semua fasilitator, partisipan, dan orang-orang yang terlibat dalam acara mengikuti protocol Covid-19 seperti mengenakan masker, menjaga jarak, dan mencuci tangan.

Pencapaian angka cakupan ASI akan terus dievaluasi pada proses pelaksanaan oleh kader yang diawasi langsung oleh Ketua Program Kasih Jeruk Purut.

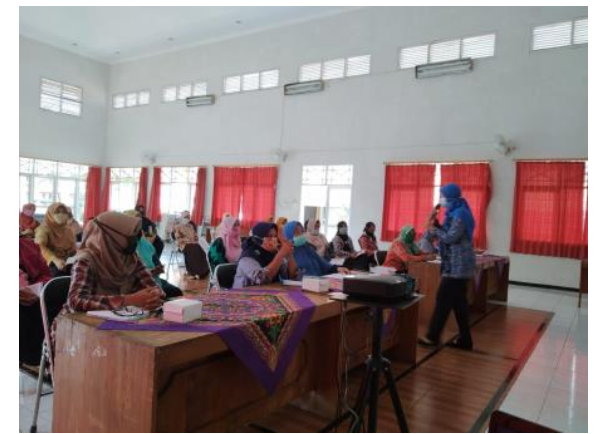

Gambar 1. Pelatihan dengan menggunakan protokol kesehatan

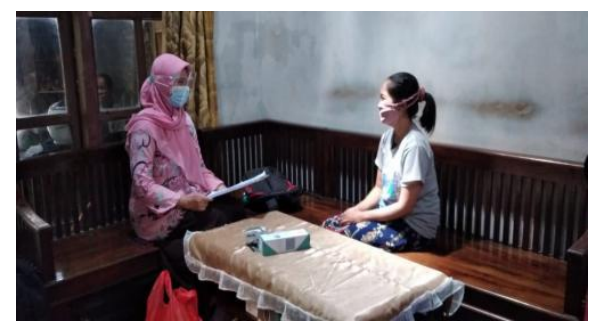

Gambar 2. Kader ASI memberi konseling kepada ibu menyusui dengan protokol kesehatan

\section{PEMBAHASAN}

Pelaksanaan kegiatan sosialisasi hari pertama dimulai pada tanggal 20 Juni 2020 di Kelurahan Bancarkembar. Tentunya sebelumnya telah dilakukan identifikasi mengenai masalah yang timbul yakni cakupan ASI yang yang kurang dari target $90 \%$. Target yang diberi sosialisasi dan pelatihan adalah para kader yang secara intens melakukan komunikasi dengan ibu menyusui. Tujuannya adalah agar kader mampu menggali informasi apa saja yang menjadi kendala ibu selama memberikan ASI sekaligus mampu memberikan penguatan dalam proses menyusui.

Beberapa hal yang perlu diperhatikan dalam pola pemberian ASI yaitu habisnya masa cuti ibu menyusui. Mereka menganggap masa kembali beraktifitas atau bekerja menjadi salah satu ham- 
Available online at https://jurnal.stmikroyal.ac.id/index.php/jurdimas

batan yang dirasa cukup besar. Hal tersebut berkaitan dengan berbagai hal yang ada di tempat kerja, seperti misalnya tidak adanya atau kurangnya fasilitas ruang laktasi yang nyaman dan waktu pumping yang kurang fleksibel. Faktor lain yang cukup memengaruhi di antaranya tidak tersedianya sarana tempat penitipan anak di sekitar tempat kerja ibu. Kecemasan akan kurang terpenuhinya ASI pada bayi sehingga ibu berfikir untuk memberikan makanan pendamping ASI selama masa enam bulan pertama kelahiran. PP Nomor 33 Tahun 2012 menghimbau agar terealisirnya kerjasama lintas sektoral dalam mendukung dan mewujudkan keberhasilan pemberian ASI Eksklusif. (Mulyana \& Rahmat, 2018). Tentunya hal-hal tersebut di atas perlu digali lebih dalam dan tentunya kader harus mampu menemukan faktor lain yang mungkin menjadi salah satu sebab permasalahan menyusui.

Pada ranah ini, peranan praktisi ASI sangat utama sebagai agent of change dalam mengubah perilaku ibu menyusui. Fasilitator dari tim pengabdian masyarakat ilmu komunikasi Universitas Amikom Purwokerto memberikan pembekalan yang dibutuhkan oleh kader yaitu bagaimana cara berkomunikasi yang efektif dengan para ibu menyusui. Pada pembekalan yang berupa pelatihan komunikasi asertif ini, fasilitator menekankan bagaimana menumbuhkan hubungan interpersonal dalam sebuah komunikasi. Pola-pola komunikasi antarpribadi memiliki pengaruh berbeda pada hubungan antarpribadi. Ada pendapat bahwa jika orang sering melakukan komunikasi antarpribadi dengan orang lain maka akan terjalin hubungan yang lebih baik. Namun, pada prinsipnya bukan kuantitas komunikasi yang dilakukan melainkan bagaimana seseorang secara berkualitas melakukan komunikasi dengan orang lain. Aspek-aspek yang menimbulkan hubungan antarpribadi di antaranya rasa percaya, sikap suportif, dan sikap terbuka.

Pelaksanaan hari berikutnya berturut-turut dilaksanakan di Grendeng, Pabuwaran dan Sumampir selama tanggal 22 hingga 27 Juni 2020. Berdasarkan informasi yang didapatkan dari ibu menyusui, beberapa di antaranya mereka tidak terbuka mengenai permasalahan yang dihadapi. Bahkan sekedar untuk bertanya pun mereka terkadang enggan dan lebih menarik diri. Ini menunjukkan tidak adanya unsur rasa percaya karena dimungkinkan ada resiko yang akan diterima, baik secara perlakuan atau ucapan dari kader. Sebenarnya keuntungan dari rasa percaya yang timbul adalah meningkatkan komunikasi antar pribadi karena adanya keterbukaan, pengiriman dan penerimaan informasi semakin jelas, serta memperluas kesempatan penerima pesan untuk mencapai apa yang dimaksud. Hilangnya kepercayaan kepada orang lain akan menghambat perkembangan hubungan interpersonal yang akrab. Keakraban hanya terjadi bila semua bersedia untuk mengungkapkan perasaan dan pikiran. Tanpa kepercayaan, akan tumbuh kegagalan komunikasi sekunder (Rakhmat, 2019).

Beberapa hal lainnya yang tidak kalah penting dalam membangun rasa percaya adalah sikap menerima, empati dan kejujuran. Menerima merupakan kemampuan berhubungan dengan orang lain tanpa menilai dan tanpa berusaha mengendalikan. Sikap menerima juga adalah sebuah sikap melihat orang lain sebagai manusia, sebagai individu yang harus dihargai. Kencenderungan individu yang senang menilai dan sukar menerima adalah sikap yang banyak dilakukan, tetapi seharusnya tidak terjadi pada kader. Pengetahuan serta kompetensi 
Available online at https://jurnal.stmikroyal.ac.id/index.php/jurdimas

kader mengenai seluk beluk ASI tidak perlu membuat kader menjadi merasa lebih tahu bahkan berperilaku seperti menyalahkan ibu menyusui jika terjadi permasalahan dalam proses menyusui. Walalupun menerima tidak berarti menyetujui semua perilaku orang lain atau rela menanggung akibat-akibat perilakunya. Menerima juga berarti tidak menilai pribadi orang berdasarkan perilakunya yang tidak disukai.

Sikap empati yang merupakan tindakan selanjutnya dari penerimaan, Freud menyatakan bahwa merupakan sebuah tindakan memahami orang lain yang tidak mempunyai arti emosional bagi kita; sebagai keadaan ketika pengamat bereaksi secara emosional karena ia menganggap orang lain mengalamai atau siap mengalami suatu emosi sebagai "imaginative intellectual and emotional participant in another person's experince"(Rakhmat, 2019). Dalam hal ini fasilitator menekankan pentingnya empati kader dalam berkomunikasi dengan ibu menyusui. Kebutuhan untuk diperhatikan, disayangi, didengarkan bahkan didukung oleh lingkungannya cukup besar. Oleh karena itu kader harus menanamkan sikap empati yang besar agar mampu memahami perasaan serta apa saja yang dibutuhkan oleh ibu menyusui, tidak terkecuali segala kekhawatiran mereka.

Pada komunikasi yang asertif dalam ranah kesehatan diperlukan sikap suportif. Pada tahapan ini, kader kesehatan harus dapat menciptakan iklim superioritas sekaligus persamaan. Superioritas artinya menunjukkan sikap lebih tinggi karena status, pengetahuan ataupun pengalaman. Namun, superioritas ini akan melahirkan sikap defensif. Sikap memperlakukan orang lain secara horisontal dan demokratis memerlukan iklim persamaan. Kader kesehatan harus dapat berbincang dengan tingkat yang sama dan tidak terkesan menggurui. Kader kesehatan berkomunikasi dengan penuh penghargaan dan penghormatan pada perbedaan sehingga komunikasi dapat berlangsung secara seimbang dan efektif.

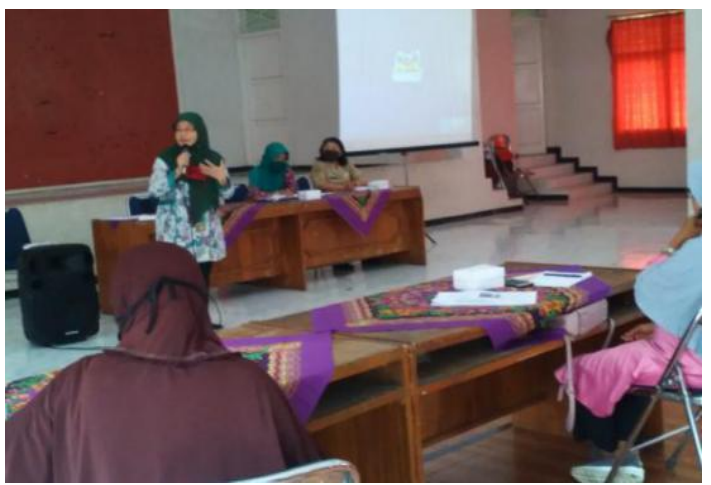

Gambar 3. Fasilitator memberikan materi

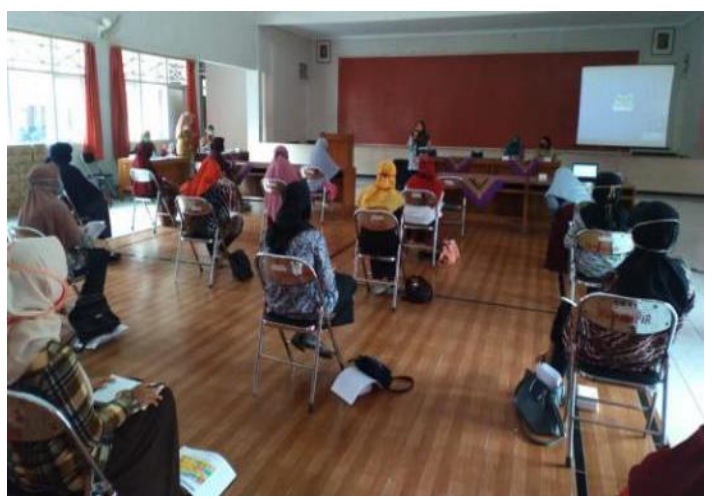

Gambar 4. Peserta pelatihan duduk dengan menjaga jarak

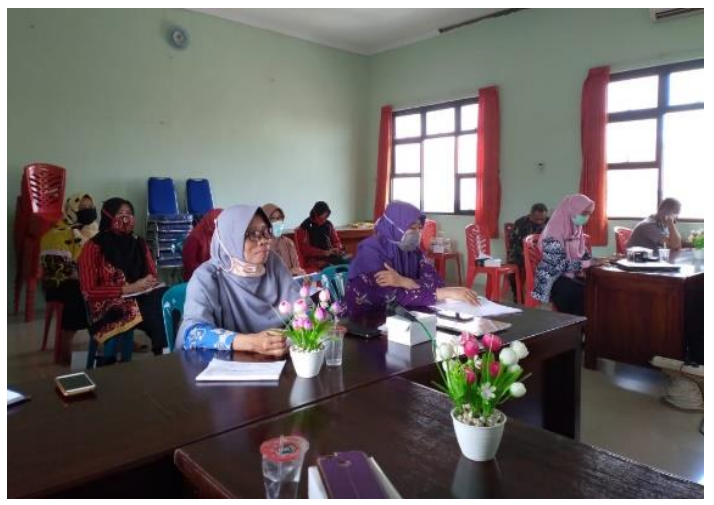

Gambar 5. Para Kader Menyimak pelatihan

Kegiatan penyuluhan yang dilakukan selama satu minggu tersebut 
Available online at https://jurnal.stmikroyal.ac.id/index.php/jurdimas

mengundang reaksi yang cukup positif baik dari kader kesehatan/ASI maupun dari pihak Puskesmas Purwokerto Utara 2. Beberapa dari kader memberikan pertanyaan dan juga memberikan umpan balik kepada fasilitator sehingga komunikasi yang terjalin cukup baik. Pertemuan yang berdurasi 2 jam tersebut memberikan masukan bagi fasilitator untuk pengabdian masayarakat bahkan penelitian selanjutnya.

\section{SIMPULAN}

Pelatihan komunikasi asertif yang melibatkan kader kesehatan/ASI dan ibu menyusui menemui kondisi komunikasi yang cukup beragam. Perbedaan field of experience antara kedua belah pihak menambah kekayaan dalam berkomunikasi sekaligus tantangan. Para kader kesehatan/ASI dan Puskesmas merasa lebih percaya diri untuk dapat meyakinkan para ibu menyusui memberikan ASI eksklusif kepada anak-anaknya dan pada gilirannya target $90 \%$ cakupan ASI dapat tercapai pada tahun 2021. Para kader kesehatan/ASI dan Puskesmas belajar menumbuhkan sikap menerima, empati, suportif, dan terbuka. Kedua belah pihak, Puskesmas dan Program Studi Ilmu Komunikasi Universitas Amikom Purwokerto berharap program pengabdian masyarakt ini dapat dilakukan secara regular sehingga hasilnya optimal.

\section{UCAPAN TERIMA KASIH}

Terima kasih kepada Kepala Puskesmas Purwokerto Utara 2, Ketua Program Inovasi Kasih Jeruk Purut, Kader kesehatan/ASI serta ibu menyusui di wilayah kerja Puskesmas Purwokerto Utara 2. Kami juga berterima kasih kepa- da Universitas Amikom Purwokerto yang mendukung terselenggaranya program, pengabdian kepada masyarakat.

\section{DAFTAR PUSTAKA}

Hadavi, M., \& Abdorrazagh Nejad, M. (2018). Assertive Behaviors Among Nursing Staff in a Local Hospital in Iran. Modern Care Journal, 15(2). https://doi.org/10.5812/modernc.80 765

Lambertz-Berndt, M. M., \& Blight, M. G. (2016). "You don't have to like me, but you have to respect me": the impacts of assertiveness, cooperativeness, and group satisfaction in collaborative assignments. Business and Professional Communication Quarterly, 79(2), 180-199. https://doi.org/10.1177/232949061 5604749

Mufdlilah. (2017). Kebijakan Pemberian ASI Eksklusif: Kendala dan Komunikasi. Yogyakarta: Nuha Medika.

Mulyana, D., \& Rahmat, D. (2018). Komunikasi Kesehatan: Pemikiran dan Penelitian. Bandung: Rosda Karya.

Omura, M., Levett-Jones, T., \& Stone, T. E. (2019). Evaluating the impact of an assertiveness communication training programme for Japanese nursing students: A quasiexperimental study. Nursing Open, 6(2), 463-472. https://doi.org/10.1002/nop2.228

Rakhmat, J. (2019). Psikologi Котиnikasi: Edisi Revisi. Bandung: Simbiosa Rekatama Media.

Sari, A. A., \& Kumorojati, R. (2019). Hubungan Pemberian Asupan Makanan Pendamping Asi (MPASI) Dengan Pertumbuhan Bayi Atau 
Jurdimas (Jurnal Pengabdian Kepada Masyarakat) Royal

Vol. 4 No. 1, Januari 2021, hlm. 51-58

DOI: https://doi.org/10.33330/jurdimas.v4i1.944

ISSN 2622-3813 (Online)

Available online at https://jurnal.stmikroyal.ac.id/index.php/jurdimas

Anak Usia 6-24 Bulan. Jurnal Kebidanan Dan Kesehatan Tradisional, 4(2), 57-119. https://doi.org/10.37341/jkkt.v4i2.1 20

Uzuntarla, Y., Cihangiroglu, N., Ceyhan,
S., \& Ugrak, U. (2016). Analysis of university students' assertiveness level. TAF Preventive Medicine Bulletin, 15(2), 98-104. https://doi.org/10.5455/pmb.11446156465 